\title{
Characterization of two orthodontic NiTi wires regarding their structures and phase transformation temperatures
}

\begin{abstract}
NiTi orthodontic wires could be considered part of clinical arsenal as a tool to improve orthodontic treatment. This paper aims at characterizing two different orthodontic NiTi wires by considering their structure and phase transformation temperatures. Nickel Titanium Memory Wire (American Orthodontics, Sheboygan, USA), and Therma-Ti (American Orthodontics, Sheboygan, USA) wires with a rectangular cross section sized $0.48 \times 0.64 \mathrm{~mm}$ were investigated by means of scanning electron microscopy (SEM), energy dispersive spectroscopy (SEM/EDS), X-ray diffraction (XRD) and differential scanning calorimetry (DSC). Both wires exhibited irregular surfaces, $\mathrm{Ni}$ and $\mathrm{Ti}$ in equal proportions whereas a $\beta$ phase was predominantly observed at room temperature. Reverse martensite temperatures obtained in the DSC experiments were in accordance with superelastic properties when considering frequent oral temperatures. These wires will be activated all the time during orthodontic treatment and should be used in cases of good periodontal health.
\end{abstract}

Volume 10 Issue 2 - 2019

\author{
Ana Cristina Rodrigues Antunes de Souza, ${ }^{1,2}$ \\ Leandro Napier de Souza, ${ }^{3}$ Alexandre Fortes \\ Drummond, ${ }^{3}$ Vicente Tadeu Lopes Buono' \\ 'Department of Metallurgical and Materials Engineering, \\ Engineering School, Federal University of Minas Gerais, Brazil \\ 2Department of Dentistry, Newton Paiva University Center, \\ Brazil \\ ${ }^{3}$ Dentistry School, Federal University of Minas Gerais, Brazil
}

\author{
Correspondence: Ana Cristina Rodrigues Antunes de Souza, \\ Avenida Silva Lobo, 1718, Nova Granada, Belo Horizonte/MG. \\ CEP 30480-230, Tel +55-31-991039997, \\ Email anacristinarasouza@gmail.com, \\ acras.prof@newtonpaiva.br
}

Received: February 25, 2019 | Published: March 05, 2019

\section{Introduction}

Nickel-Titanium (NiTi) alloys have been used in orthodontics due to its superelasticity (SE) and shape-memory effect (SME), through which they release constant, low magnitude forces during clinical practice. ${ }^{1-3}$ SE and SME are considered to constitute the typical behavior of NiTi alloys. Nevertheless, shape recovery following removal of tension is due to SE while SME is dependent on temperature. ${ }^{4}$ These alloys present two main phases: austenite, stable at high temperatures; and martensite, induced during stress or at low temperatures. Martensite induced by low temperature is called macled martensite and features 24 variations of cristallography orientation, whereas in stress-induced martensite, variants are oriented to become a single arrangement according to the tension applied. ${ }^{5} \mathrm{NiTi}$ orthodontic alloys are classified as martensitic, referring to a stable martensite without phase changes, ${ }^{6}$ superelastics or those with austenitic activation, in which deformation occurs by stress-induced martensite, returning to the austenitic phase after tension removal; ${ }^{7}$ shape memory alloys or those with martensitic activation, in which deformation occurs in temperatures lower than oral ones by intentionally refrigerating the wire into a full martensite condition. When it reaches the alloy austenitic finish temperature $\left(A_{f}\right)$, the wire tries to return to its austenitic structure. ${ }^{4}$ In the case of tension removal in temperatures higher than $\mathrm{A}_{\mathrm{f}}$, unloading occurs by stress-induced martensite, involving superelasticity. ${ }^{7}$ A variety of new orthodontic wires presenting distinct themomechanical properties has multiplied clinical choice options. Thus, learning about the properties of such wires has become necessary for better clinical application. The purpose of this paper is the characterization of two different orthodontic NiTi wires regarding their structures and phase transformation temperatures.

\section{Materials and methods}

\section{Materials}

Nickel Titanium Memory Wire (American Orthodontics, Sheboygan, WI, USA) and Therma-Ti (American Orthodontics,
Sheboygan, WI, USA) wires with rectangular cross sections, measuring $0.48 \mathrm{~mm} \times 0.64 \mathrm{~mm}$ were studied.

\section{Scanning Electron Microscopy (SEM)}

Surface morphological aspects of orthodontic wires, as received from manufacturer, were analyzed by means of SEM. The wires, randomly chosen, were cleaned inside an ultrasonic cube with Acetone PA. Samples were analyzed by SEM model JSM 5410 (Jeol, Tokyo, Japan). Five $30 \mathrm{~mm}$-long segments of each wire were set in a sample holder deprived of $\mathrm{Ni}, \mathrm{Ti}$ and $\mathrm{Cu}$. Ten points of each wire segment were analyzed.

\section{Energy-Dispersive Spectroscopy (SEM/EDS)}

Thirty millimeters of each wire, as received from manufacturer, were used by means of SEM/EDS with Spectrometer $T N-M 3055$ (Noran, Middleton, WI, USA) coupled to SEM JSM 5410 (Jeol, Tokyo, Japan). Five $30 \mathrm{~mm}$-long segments of each wire were set in a sample holder deprived of $\mathrm{Ni}$, $\mathrm{Ti}$ and $\mathrm{Cu}$. Analysis was carried out in ten points of each wire segment randomly chosen and previously cleaned with Acetone PA in an ultrasonic bath.

\section{X-Ray Diffraction (XRD)}

Wires, as received from manufacturer, were cut in ten $15 \mathrm{~mm}$-long pieces and placed side by side over an adhesive tape. These samples were submitted to X-ray diffraction (XRD) with PW-1710 (Philips PANalytical, Almelo, The Netherlands) under room temperature conditions. Three sets of ten $15 \mathrm{~mm}$-long wire segments were tested and analyzed at room temperature with $\mathrm{Cu}-\mathrm{K} \alpha$ radiation. Diffraction peaks were indexed according to APD software (Philips-PANalytical, Almelo, The Netherlands) and electronic charts from ICDD (International Committee for Diffraction Data).

\section{Differential Scanning Calorimetry (DSC)}

In order to evaluate transformation temperatures, wires, as received from manufacturer, were cut in pieces with adequate pliers. 
The mass of the pieces altogether amounted to approximately $10 \mathrm{mg}$. Each wire was tested three times by DSC (DSC60, Shimadzu, Kyoto, Japan) with temperature rising to $80^{\circ} \mathrm{C}$ and then falling to $-80^{\circ} \mathrm{C}$ under nitrogen atmosphere, at a heating $/$ cooling rate of $10^{\circ} \mathrm{C} / \mathrm{min}$.

\section{Results}

\section{Surface topography}

Images obtained by SEM showed superficial roughness and structures such as pitch corrosion on the rectangular face (Figure 1ab) and on the corner (Figure 1c) of the Nickel Titanium Memory Wire. Regarding the Therma-Ti wire, the surfaces presented with similar aspects to the first one (Figure 2).

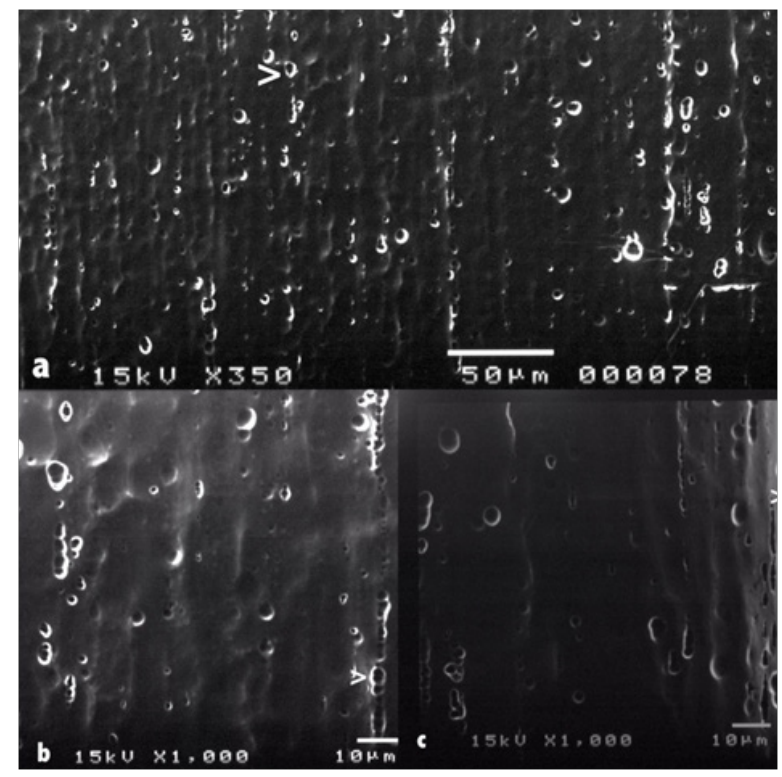

Figure I SEM images of Nickel Titanium Memory Wire. A: Rectangular face exhibiting corrosion pitches (White arrows) and surface irregularities $(350 \mathrm{x})$; B: (I,000 x) e; c:Wire corner $(I, 000 \mathrm{x})$.

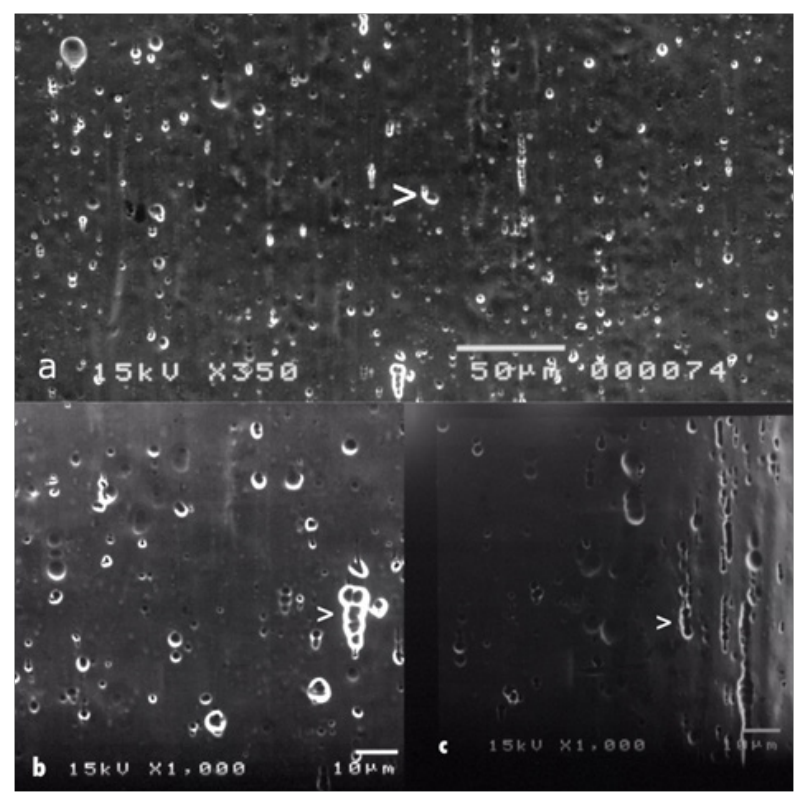

Figure 2 SEM images obtained of Therma-Ti. a: Rectangular face exhibiting corrosion pitches (White arrows) and surface irregularities (350 x); b: (I,000 $\mathrm{x})$ e; c:Wire corner $(\mathrm{I}, 000 \mathrm{x})$.

\section{Elementary chemical composition}

Figures $3 a$ and $3 b$ show SEM/EDS analysis of 10 different areas on the wires revealing spectrum peaks and average values of the elements findings. SEM/EDS analysis revealed an equiatomic proportion of $\mathrm{Ni}$ and $\mathrm{Ti}$ in accordance with the requisites for shape memory effect. ${ }^{8}$ Alloys with more than 51.6 at\% Ni became hard and friable. ${ }^{8}$ Besides alloys enriched with Ni present the best SE and SME. ${ }^{9}$ Both wires displayed these characteristics, which corroborate Fischer-Brandies et al's study. ${ }^{10}$
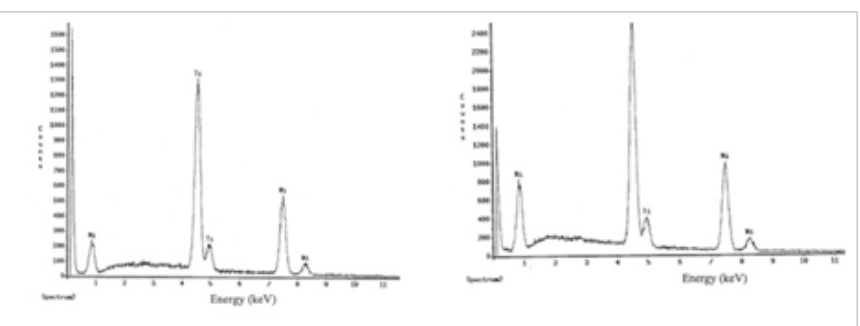

A
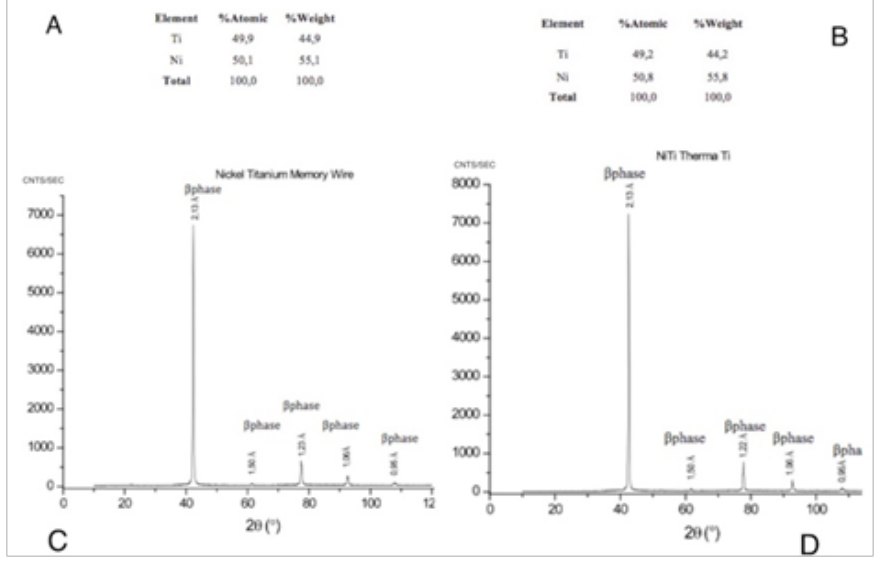

Figure $3 \mathrm{~A}$ : SEM/EDS spectrum of Nickel Titanium Memory Wire and average values of elements. B: SEM/EDS spectrum of Therma-Ti wire and average values of elements. C: X-ray diffractogram of Nickel Titanium Memory Wire showing $\beta$ phase. D:X-ray diffractogram of Therma-Ti showing $\beta$ phase.

\section{Main phases at room temperature}

XRD results showed all samples bearing an austenite phase $(\beta)$, but not a martensitic phase (B19') at room temperature (Figures 3c and d). ${ }^{11}$ These findings are favorable to SME since no other metallic phases were formed, ${ }^{12}$ thus indicating that both wires show SE under deformation at room and common oral temperatures.

\section{Phase transformation temperature assessment}

Results allowed evaluation of the martensite transformation temperature of wires. The average $\mathrm{A}_{\mathrm{f}}$ temperature for Nickel Titanium Memory Wire was $9.8^{\circ} \mathrm{C}$, lower than frequent intraoral temperatures, resulting in the presence of the austenitic phase and, consequently, SE, almost all along the orthodontic treatment (Table 1). DSC results are in accordance with XRD results for these samples, since $\mathrm{A}_{\mathrm{f}}$ temperature was $9.8^{\circ} \mathrm{C}$, lower than room temperature. The wire presented a peak during the heating, corresponding to austenite nucleation, and a peak during the cooling, corresponding to martensite nucleation. R Phase was not present (Figure 4).

Average $\mathrm{A}_{\mathrm{f}}$ temperature was $21.1^{\circ} \mathrm{C}$ for Therma-Ti wire with the austenitic phase present almost all the time, considering normal oral temperatures. Average martensitic finish temperature $\mathrm{M}_{\mathrm{f}}\left(-49.1^{\circ} \mathrm{C}\right)$ and martensitic start temperature $\mathrm{M}_{\mathrm{s}}\left(-39.1^{\circ} \mathrm{C}\right)$ (Table 1) will not be 
reached in normal conditions, except during intentional freezing, favoring the SME effect in this wire. ${ }^{13}$ DSC results are in accordance with XRD results for these samples as well. The R phase appearance (Figure 5) probably was due to the occurrence of coherent precipitates $\left(\mathrm{Ni}_{4} \mathrm{Ti}_{3}\right)$ in the austenitic matrix during annealing. ${ }^{9}$ In this case, an increase in the cold work associated with annealing at about $500^{\circ} \mathrm{C}$ was possibly used to stabilize the $\mathrm{R}$ phase. ${ }^{14-16}$ The manufacturer did not provide information about the phase transformation temperature of the wires, but results presented herein confirmed their superelasticity property during clinical use. Therefore, both wires will facilitate dental alignment and leveling during orthodontic treatment. Moreover, Therma-Ti wire could be more easily installed in dental brackets after intentional freezing, before clinical use, due to its SME.

Table I Comparison between austenitic start temperatures $\left(A_{s}\right)$, martensitic finish temperatures $\left(A_{f}\right)$, $R$-phase start temperatures $\left(R_{s}\right)$ and $R$-phase finish temperatures $\left(R_{f}\right)$ of Nickel Titanium Memory Wire and Therma-Ti wire

\begin{tabular}{lllllll}
\hline Sample & $\mathbf{M}_{\mathrm{s}}$ & $\mathbf{M}_{\mathbf{f}}$ & $\mathbf{R}_{\mathrm{s}}$ & $\mathbf{R}_{\mathbf{f}}$ & $\mathbf{A}_{\mathrm{s}}$ & $\mathbf{A}_{\mathbf{f}}$ \\
\hline $\mathrm{NTMW}$ & $2,5( \pm 0,4)^{\circ} \mathrm{C}$ & $-5,8( \pm 0,6)^{\circ} \mathrm{C}$ & ------ & $-\cdots$ & $1,4( \pm 0,8)^{\circ} \mathrm{C}$ & $9,8( \pm 0,9)^{\circ} \mathrm{C}$ \\
$\mathrm{TT}^{2}$ & $-39,1( \pm 0,5)^{\circ} \mathrm{C}$ & $-49,1( \pm 0,1)^{\circ} \mathrm{C}$ & $8,4( \pm 0,7)^{\circ} \mathrm{C}$ & $3,2( \pm 0,2)^{\circ} \mathrm{C}$ & $11,7( \pm 1,9)^{\circ} \mathrm{C}$ & $21,1( \pm 0,5)^{\circ} \mathrm{C}$ \\
\hline
\end{tabular}

'Nickel titanium memory wire; ${ }^{2}$ Therma-Ti

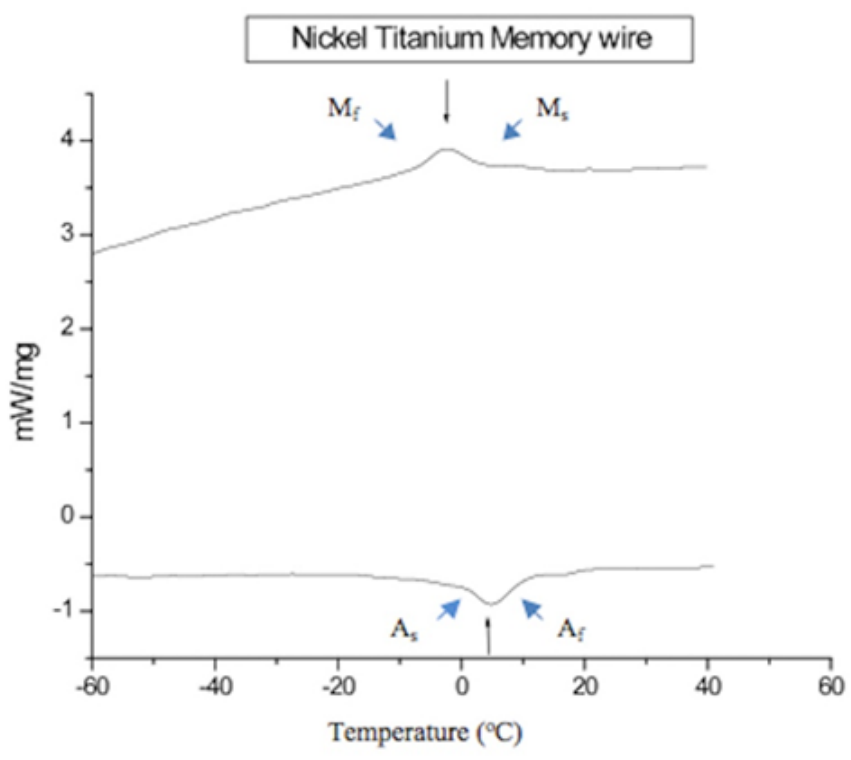

Figure 4 DSC heating and cooling curves for nickel titanium memory wire.

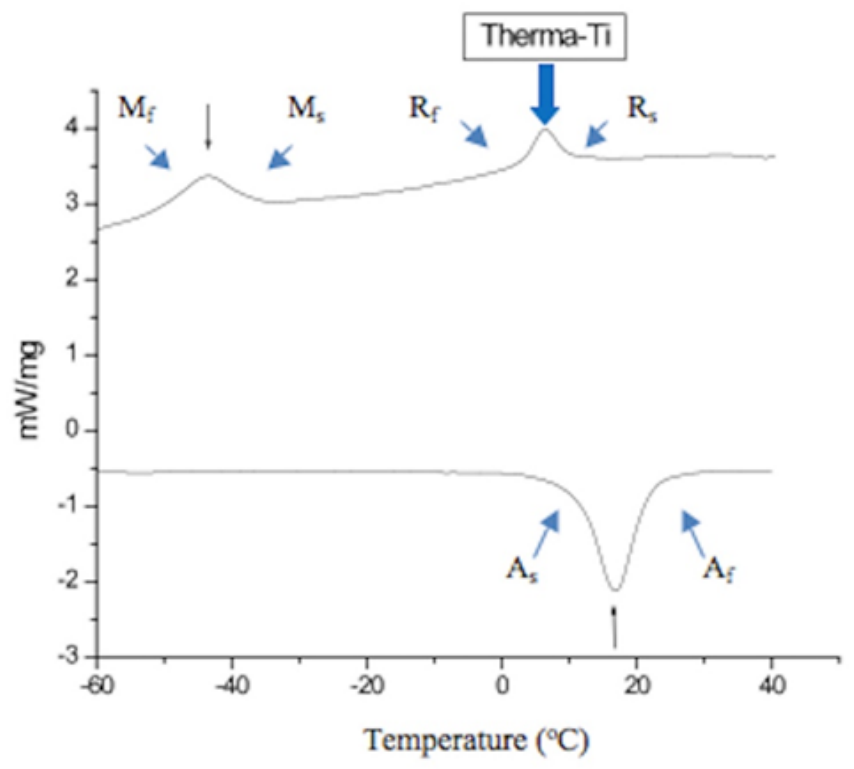

Figure 5 DSC heating and cooling curves for Therma-Ti wire. The blue arrow indicates the R-phase peak.

\section{Discussion}

\section{Surface Topography}

Images obtained by SEM showed superficial roughness and structures such as pitch corrosion on the rectangular face (Figure 1a and b) and on the corner (Figure 1c) of the Nickel Titanium Memory Wire. These findings were probably caused by the fluoridric acid used for chemical polishing ${ }^{17}$ and are in accordance with results of other studies that evaluated NiTi wire surfaces by SEM. ${ }^{10,18}$ Regarding Therma-Ti wire, surfaces presented with aspects similar to the first one (Figure 2). Surface characteristics are related to a material's corrosion resistance and the possible allergic reactions associated with release of Nickel. ${ }^{19,20}$ Moreover, they could affect friction between the wire and the slot of the brackets, ${ }^{10}$ leading to a decrease in effectiveness and an increase (in intensity) of forces applied during clinical practice, thus increasing the risk of root and bone resorptions. An increase in dental plaque accumulation on the irregular surface of wires will lead to more difficulty in its removal and, consequently, hinder dental hygiene.

\section{Elementary chemical composition}

Figures $3 \mathrm{a}$ and $3 \mathrm{~b}$ show SEM/EDS analysis of 10 different areas on the wires revealing spectrum peaks and average values of element findings. SEM/EDS analysis revealed an equiatomic proportion of $\mathrm{Ni}$ and $\mathrm{Ti}$ in accordance with the requisites for shape memory effect. ${ }^{8}$ Alloys with more than $51.6 \mathrm{at} \% \mathrm{Ni}$ became hard and friable. ${ }^{8}$ Besides alloys enriched with Ni present the best SE and SME characteristics. ${ }^{9}$ Both wires displayed these characteristics, which corroborate FischerBrandies et al's study. ${ }^{10}$

\section{Main phases at room temperature}

XRD results showed all samples bearing an austenite phase ( $\beta$ ), but not a martensitic phase (B19') at room temperature ${ }^{11}$ (Figures 3c and 3d). These findings are favorable to SME since no other metallic phases were formed, ${ }^{12}$ thus indicating that both wires show SE under deformation at room and common oral temperatures.

\section{Phase transformation temperature assessment}

Results allowed evaluation of the martensite transformation temperature of wires (Figures 4,5 and Table 1). The average $A_{f}$ temperature for Nickel Titanium Memory Wire was $9.8^{\circ} \mathrm{C}$, lower than frequent intraoral temperatures, resulting in the presence of the austenitic phase and, consequently, SE, almost all along the orthodontic treatment (Table 1). DSC results are in accordance with 
XRD results for these samples, since $\mathrm{A}_{\mathrm{f}}$ temperature was $9.8^{\circ} \mathrm{C}$, lower than room temperature. The wire presented a peak during the heating, corresponding to austenite nucleation, and a peak during the cooling, corresponding to martensite nucleation. $\mathrm{R}$ Phase was not present (Figure 4).

Average $\mathrm{A}_{\mathrm{f}}$ temperature was $21.1^{\circ} \mathrm{C}$ for Therma-Ti wire with the austenitic phase present almost all the time, considering normal oral temperatures. Average martensitic finish temperature $\mathrm{M}_{\mathrm{f}}\left(-49.1^{\circ} \mathrm{C}\right)$ and martensitic start temperature $\mathrm{M}_{\mathrm{s}}\left(-39.1^{\circ} \mathrm{C}\right)$ (Table 1) will not be reached in normal conditions, except during intentional freezing, favoring the SME effect in this wire. ${ }^{13}$ DSC results are in accordance with XRD results for these samples as well. The R phase appearance (Figure 5) probably was due to the occurrence of coherent precipitates $\left(\mathrm{Ni}_{4} \mathrm{Ti}_{3}\right)$ in the austenitic matrix during annealing. ${ }^{9}$ In this case, an increase in the cold work associated with annealing at about $500^{\circ} \mathrm{C}$ was possibly used to stabilize the R phase. ${ }^{14-16}$ The manufacturer did not provide information about the phase transformation temperature of the wires, but results presented herein confirmed their superelasticity property during clinical use. Furthermore, since $A_{f}$ temperatures are lower than oral temperatures, the wires will be activated all the time, and so, more indicated to patients with heath periodontal status. ${ }^{21}$ Moreover, Therma-Ti wire could be more easily installed in dental brackets after intentional freezing, before clinical use, due to its SME.

\section{Conclusion}

Both wires have SE behavior during clinical use. SME could only be noticed under intentional freezing in Thema-Ti wire. Assays did not represent real clinical conditions, but the knowledge of wires $\mathrm{A}_{\mathrm{f}}$ temperatures could help clinicians in the correct choice to each patient, considering the periodontal health.

\section{Acknowledgments}

This work was partially supported by grants of Fundação de Amparo à Pesquisa do Estado de Minas Gerais (FAPEMIG), Belo Horizonte, MG, Brazil, and Conselho Nacional de Desenvolvimento Científico e Tecnológico (CNPq), Brasília, DF, Brazil. Dr. Vicente Tadeu Lopes Buono is a fellow researcher of CNPq.

\section{Conflicts of interest}

The authors declare that there is no conflict of interest.

\section{References}

1. Mallory DC, English JD, Powers WM, et al. Force-deflection comparison of superelastic nickel-titanium archwires. Am J Orthod Dentofacial Orthop. 2004;126(1):110-112.

2. Lombardo L, Marafioti M, Stefanoni F, et al. Load deflection characteristics and force level of nickel titanium initial archwires. Angle Orthodontist. 2012;82(3):507-521.

3. Kusy RP, Greenberg AR. Comparison of elastic properties of nickeltitanium and beta titanium archwires. Am J Orthod. 1982;82(3):199-205.
4. Otsuka K, Ren X. Physical metallurgy of Ti-Ni-based shape memory alloys. Prog Mater Sci. 2005;50:511-678.

5. Saburi T. Ti-Ni shape memory alloys. In: Otsuka K, Waymann CM. Shape memory materials. Cambridge: Cambridge University Press; 1998:49-96.

6. Kusy RP. Nitinol alloys: so, who's on first? Letter to the editor. Am J Orthod Dentofacial Orthop. 1991;100(3):25A-26A.

7. Miyazaki T, Hashinaga K, Yumikura H, et al. Shape memory characteristics of sputter-deposited Ti-Ni-base thin films, Smart Materials. SPIE Proc Series. 1995;2441:156-164.

8. Raz SB, Sadrnezhaad SK. Effects of VIM frequency on chemical composition, homogeneity and microstructure of NiTi shape memory alloy. Mater Sci Tech. 2004;20:593-538.

9. Otsuka K, Ren X. Physical metallurgy of Ni-Ti-based shape memory alloys. Prog Mater Sci. 2005;50:511-678.

10. Fischer-Brandies H, Es-Souni M, Kock N, et al. Transformation behavior, chemical composition, surface topography and bending properties of five selected $0.016 " \mathrm{X} 0.022$ " NiTi archwires. Journal of Orofacial Orthopedics. 2003;64(2):88-89.

11. Iijima M, Ohno H, Kawashima I, et al. Micro X-ray diffraction study of superelastic nickel-titanium orthodontic wires at different temperatures and stresses. Biomaterials. 2002;23:1769-1774.

12. McNeese MD, Lagoudas DC, Pollock C. Processing of NiTi from elemental powders by hot isostatic pressing. Mater Sci Eng A. 2000;280(2):334-348.

13. Moore RJ, Watts JTF, Hood JAA, et al. Intra-oral temperature variation over 24 hours. Eur J Orthod. 1999;21(3):249-261.

14. Miller AD, Lagoudas DC. Influence of cold work and heat treatment on the shape memory effect and plastic strain development of NiTi. Materials Science and Engineering A. 2001;308 (1-2):161-175.

15. Kurita T, Matsumoto H, Abe H. Transformation behaviour in rolled NiTi. Journal of Alloys and Compounds. 2004;381:158-161.

16. Ramaiah VK, Saikrishna CN, Bhaumik SK. Processing of Ni-Ti Shape Memory Alloy Wires. Proceedings of International Conference on Smart Materials Structures and Systems. 2005:141-147.

17. Zhao H, van Humbeeck J, De Scheerder I. Surface Conditioning of Nickel-titanium Alloy Stents for Improving Biocompatibility. Surface Engineering. 2001;17(6):451-458.

18. Doshia UH, Bhad-Patil WA. Static frictional force and surface roughness of various bracket and wire combinations. Am J Orthod Dentofacial Orthop. 2011;139(1):74-79.

19. Dunlap CL, Vincent K, Barker BF. Allergic reaction to orthodontic wire. Report of case. J Am Dent Assoc. 1989;118(4):449-450.

20. Bass JK, Fine H, Cisneros J. Nickel hypersensitivity in the orthodontic patient. Am J Orthod Dentofac Orthop. 1993;103(3):280-285.

21. Sachdeva RCL. Ortodontia com temperatura de transformação variável. Copper Ni-Ti torna isto uma realidade. Clinical Impressions. 1997;1(1):2-9. 